\title{
Models for Describing Knowledge Sharing Practices in the Healthcare Industry: Example of Experience Knowledge Sharing
}

\author{
Negar Monazam Tabrizi \\ University of Manchester, United Kingdom
}

\author{
Sharon Morgan \\ University of Manchester, United Kingdom
}

\begin{abstract}
Healthcare organisations have recently realised that medical knowledge not only needs to be managed but also shared among professionals and patients. Inadequate knowledge sharing in healthcare organisations can lead to medical errors. As a result, knowledge sharing in healthcare industry may no longer be a "nice to have" process but changes into a "must have" one. Acknowledgement of the importance of knowledge sharing in healthcare organisations has resulted in a number of studies in exploring and examining this phenomenon. Most of these valuable contributions are related to the nature of knowing, knowledge sharing means, and governance mechanisms. Despite the richness and depth in these three streams of research, none of the existing studies integrate these three concepts. And hence, there remains uncertainty about the intrinsic relationship among these three kinds of concepts. It is thus worthwhile to examine firstly, the relationship among these concepts and secondly, their impact on knowledge sharing performance. This study provides a comprehensive view of knowledge sharing practices from the three mentioned perspectives. A model for these three aspects of knowledge sharing practices is built through literature review, and the relationship among them is explored. It is proposed that both knowledge sharing means and governance mechanism impact the knowledge sharing process directly. Additionally, the governance mechanism has an indirect impact on the knowledge sharing process by influencing the choice and usage of the means. This study will provide organisations and policy makers with a framework to better understand knowledge sharing practices from different perspectives. This study applies the proposed model of the study as a core analytical framework to find out how strong experience knowledge sharing can be achieved and explain the reasons of that.
\end{abstract}

Paper type: Research paper

Keywords: Knowledge Sharing, Knowledge Sharing Process, Knowledge Sharing Means, Governance Mechanism, Healthcare, Experience Knowledge Sharing 


\section{Introduction}

Knowledge has been regarded as an essential source of value creation in recent studies (Poston and Speier, 2005). The availability of accurate and timely knowledge enables organisations to respond rapidly and with the appropriate measures to create high quality services, products, and processes (Nonaka et al., 2000). Therefore, the competitive advantage of organisations lies in their ability to effectively manage knowledge. However, individuals and organisations are faced with huge amounts of data and information which is crucial in nature but hard to manage appropriately (Carayannis, 2005). Therefore, a business philosophy namely Knowledge Management $(\mathrm{KM})$ has been introduced. $\mathrm{KM}$ is concerned with all processes related to knowledge creation, storage, sharing, and application (Alavi and Leidner, 2001). Since the benefit of knowledge is limited if it is not shared, knowledge sharing is perceived to be the most important process of KM (Leonard-Barton, 1995). Knowledge sharing is especially important in industries where knowledge is a key asset like healthcare organisations. The healthcare industry is a knowledge rich community which deals with patients' lives and wellness. Losing the opportunity of having the right knowledge at the right time can lead to medical errors (Kilo, 2005). Therefore, knowledge sharing is a must in healthcare organisations.

Consequently, many studies have attempted to understand knowledge-sharing practices in the healthcare industry from different perspectives. Most of these contributions are about the nature of knowing (e.g. Miller, 2012; Zigan et al. 2010), knowledge sharing means (e.g. Bradley et al., 2012; Ozdemir et al., 2011), and knowledge sharing governance mechanisms (e.g. Currie and Suhomlinova, 2006; Aron et al., 2011). Despite the richness and depth in these three streams of research, at present there is no study integrating these various insights. Therefore, there remains uncertainty about the intrinsic relationship among these concepts as knowledge sharing is a combination of process, technology, and people and cannot be considered in isolation (Awad and Ghaziri, 2007). Thus, it is worthwhile to examine firstly, the relationship among these concepts and secondly, their impact on knowledge sharing performance.

This study provides a comprehensive view of knowledge sharing practices from the three mentioned perspectives. A model for these three aspects of knowledge sharing practices is built through literature review, and the relationship among them is explored. We intend to apply this model as a critical theoretical tool for understanding Experience Knowledge Sharing (EKS) in the healthcare industry.

The study is organised as follows. First, the concept of knowledge sharing is discussed in general and in the healthcare industry in particular. Next, the research methodology is described. The knowledge sharing process, knowledge sharing means, and knowledge sharing governance mechanisms are respectively discussed in the following sections. Further, the relationship among these concepts is explored and the research model of the study is proposed. EKS analysis is done in the following section. Finally, we conclude with the discussion of key findings. 


\section{Knowledge sharing}

Knowledge sharing can be defined as "team members sharing task-relevant ideas, information, and suggestions with each other" (Sirvastava et al., 2006; p.4). The availability of shared knowledge is necessary for adapting, extending and creating new knowledge and innovation (Hislop, 2007). Knowledge sharing is a people to people process and sometimes is difficult to implement. Also, knowledge sharing is severely constrained in the absence of knowledge sharing means. Reliable knowledge and effective communication are critical factors that can be achieved by use of appropriate knowledge sharing means (Bradley et al., 2012). Therefore, managing knowledge and people effectively and using proper knowledge sharing means is key to a successful knowledge sharing practice. To study these factors deeply, it is also necessary to study knowledge sharing process. Thus, our view is that; three factors influence knowledgesharing performance, that is, Knowledge Sharing Process (KSP), Knowledge Sharing Means (KSM), and Knowledge Sharing Governance Mechanisms (KSGM). Knowledge sharing process refers to the nature of knowing and the stages of how knowledge is shared from one party to another. Knowledge sharing means refers to what kinds of means are adopted to realise the movement of knowledge during the process of knowledge sharing. Knowledge sharing governance mechanisms can be defined as how the event in each stage is supported or motivated during the knowledge sharing process.

\subsection{Knowledge sharing in the healthcare industry}

According to the Lin and Hsieh (2006), delivering safe and high quality services to patients is highly dependent on sharing the following types of knowledge, i.e. medical knowledge, scientific knowledge, incident knowledge, and experience knowledge. Medical knowledge is defined as the required information for diagnosis and treatment (Aron et al., 2011). Scientific knowledge is about applying research findings in practice (Ho et al., 2004). Incident knowledge refers to learn from medical errors (Sim et al., 2001). Finally, experience knowledge refers to experienced healthcare providers educate less experienced practitioners about the best practice procedures (Stead and Lin, 2009).

Failure to share the above mentioned knowledge can impact patient safety (Lin and Hsieh, 2006). Thus, all these types of knowledge require special attention, in order to create an environment to improve the quality of healthcare services. EKS, however, is a more fragile process amongst other of types of knowledge due to the tacit nature of experience knowledge and people's diverse intentions. Knowledge, especially experience knowledge, is a valuable asset which is often considered as a source of power so people might be reluctant to share their knowledge to others or look suspiciously upon knowledge from others (Kankanhalli et al., 2005). Although there are substantial research efforts on knowledge sharing in the healthcare industry as a distinct body of knowledge, there is a dearth of research on addressing EKS. Therefore, we have a limited understanding of how healthcare organisations create, access, and share experience knowledge. In order to address this issue, we focus on EKS in our research.

Decision-making in medicine as in all fields of professional practice includes internal information and external information, what Norman (1998) conceptualised as "knowledge in the head" and "knowledge in the world". Many decisions will be made 
based on the healthcare providers' own personal knowledge, but other decisions will be informed by communicating with professional colleagues and etc. (Sim et al., 2001). Decision making according to personal knowledge alone uses minimum time, which is a scarce resource in healthcare organisations, but every health professional's personal knowledge is incomplete in different ways. Decisions according to incomplete or outdated personal knowledge can lead to medical errors. Therefore, senior clinicians have an important role in educating junior clinicians (Mansingh et al., 2009).

\section{Methodology}

This study collected articles dated from $2000-2012$ by using a systematic review to explore the knowledge-sharing phenomenon from a broad view. The literature mainly came from the journals in field of Healthcare, KM, and Information Technology (IT). Three top journals from each research field were chosen. Then, each journal was searched issue by issue by looking at paper titles and abstracts. For any that were relevant to knowledge sharing in healthcare, the full text would be read. The breakdown of sources that contributed to the final report is shown in Figure 1.

Figure 1: Summary of Sources Contributing to the Systematic Review

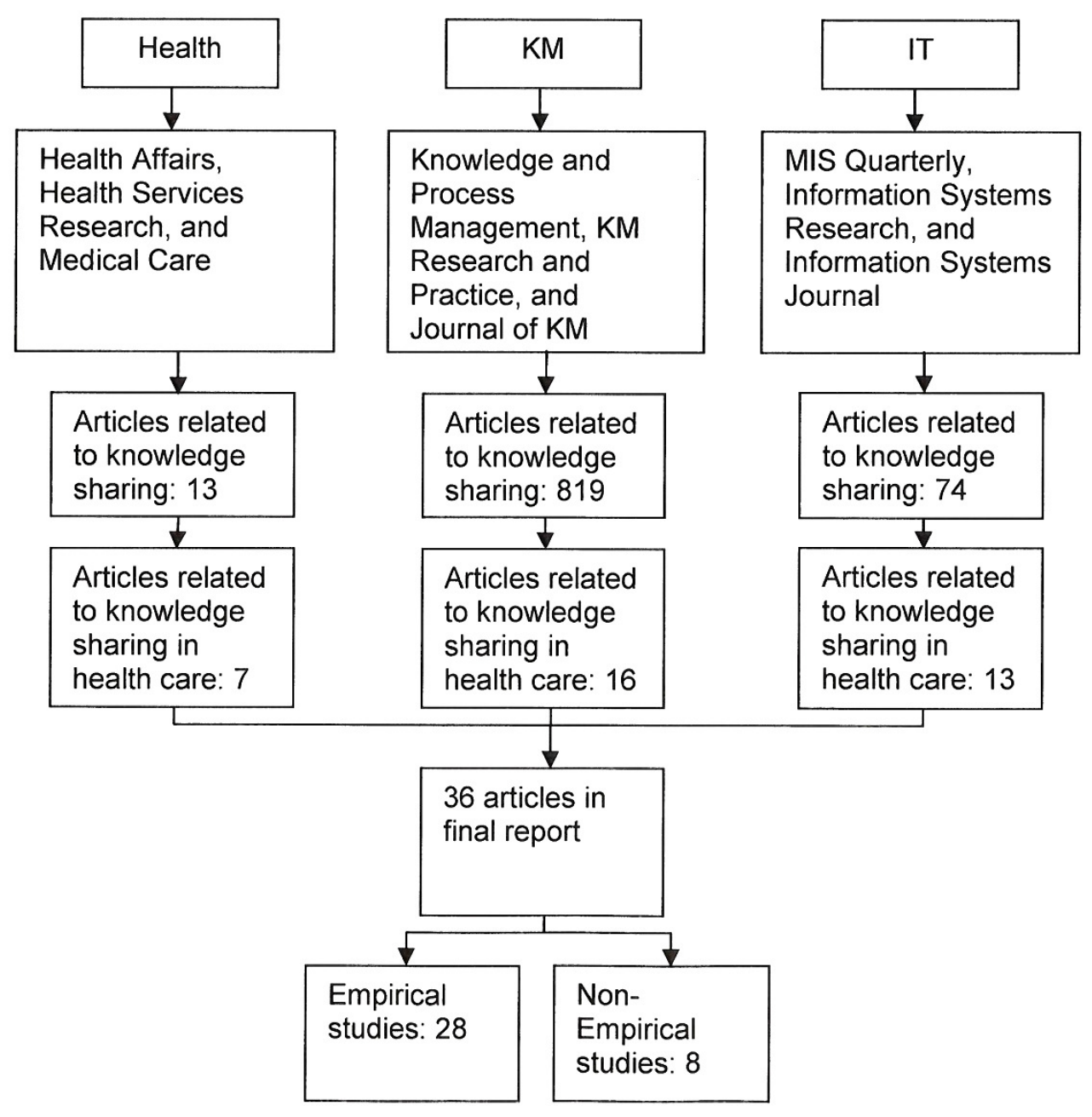

International Journal of Management and Applied Research, 2014, Vol. 1, No. 2 
The systematic review of the literature helped us to identify three comprehensive themes that have occupied the authors' interests: the nature of knowing (knowledge sharing process), knowledge sharing means, and knowledge sharing governance mechanisms. Based on this analysis, a model for these three aspects of knowledge sharing is built through the literature review and the relationship among them is explored.

This model, then, is applied as a critical theoretical tool for understanding EKS. To do this, the author adopted a qualitative approach to investigate enablers and/or barriers to sharing experience knowledge. A hospital in the UK was selected and necessary data was collected by using a semi-structured interview method. A total of 15 healthcare providers were interviewed. The sample was selected based on healthcare providers' interest and availability. Each interview lasted 45 minutes and they were audio-recorded with permission and transcribed. To analyse the data, template analysis was employed. The researcher produced a list of codes that represent the components in the model, i.e. knowledge sharing governance mechanisms, knowledge sharing means, and knowledge sharing process. This template used to identify the factors that impact the performance of EKS in each step of knowledge sharing process.

\section{Knowledge sharing process}

While knowledge sharing has been treated as a black box by most of the scholars, small but important streams of the literature discussed the knowledge sharing process. Davenport and Prusak (1998), Lin et al. (2005), and Hansen (1999) suggested a twostage model: sending and receiving the knowledge. Based on their model, knowledge source first collects the necessary parts of knowledge and sends the required knowledge to the knowledge receiver. Then, knowledge receiver receives the knowledge transferred, absorbs it and removes the noise in it to obtain the useful part of knowledge to solve the target problem.

Szulanski (1996) proposed a model with four stages: Initiation, Implementation, Rampup, and Integration. This model is developed based on the investigations of the rich empirical researches on technology transfer, social change, innovation diffusion, and implementation. Based on their model, a four-stage model is developed in this study which is shown in Figure 2. The proposed model of this study differs from the previous models in several ways:

- The knowledge sharing process is also analysed from the perspective of project management, since they have some similar processes (Busby, 1999; Kamara et al., 2002). Investigating knowledge sharing in this way helps to overcome some limitations in unpicking knowledge sharing.

- Our model considers another stage namely, requirements stage, as the requirements associated with the sharing of knowledge need to be specified as clearly as possible.

- Our model also adds another stage called follow-up stage. Despite the importance of follow-up stage, this phase is often neglected. The net benefits and acquired relevant experiences and lessons which can reflect the effect of shared knowledge can be clarified in this stage. 
- Our model considers ramp-up and integration stages as activities of implementation stage and labels the ramp-up stage as knowledge absorption and utilisation.

- In our model, the stages of the knowledge sharing process are subdivided into several specific sub-stages, in order to make knowledge sharing clearer.

Figure 2: A model of knowledge sharing process

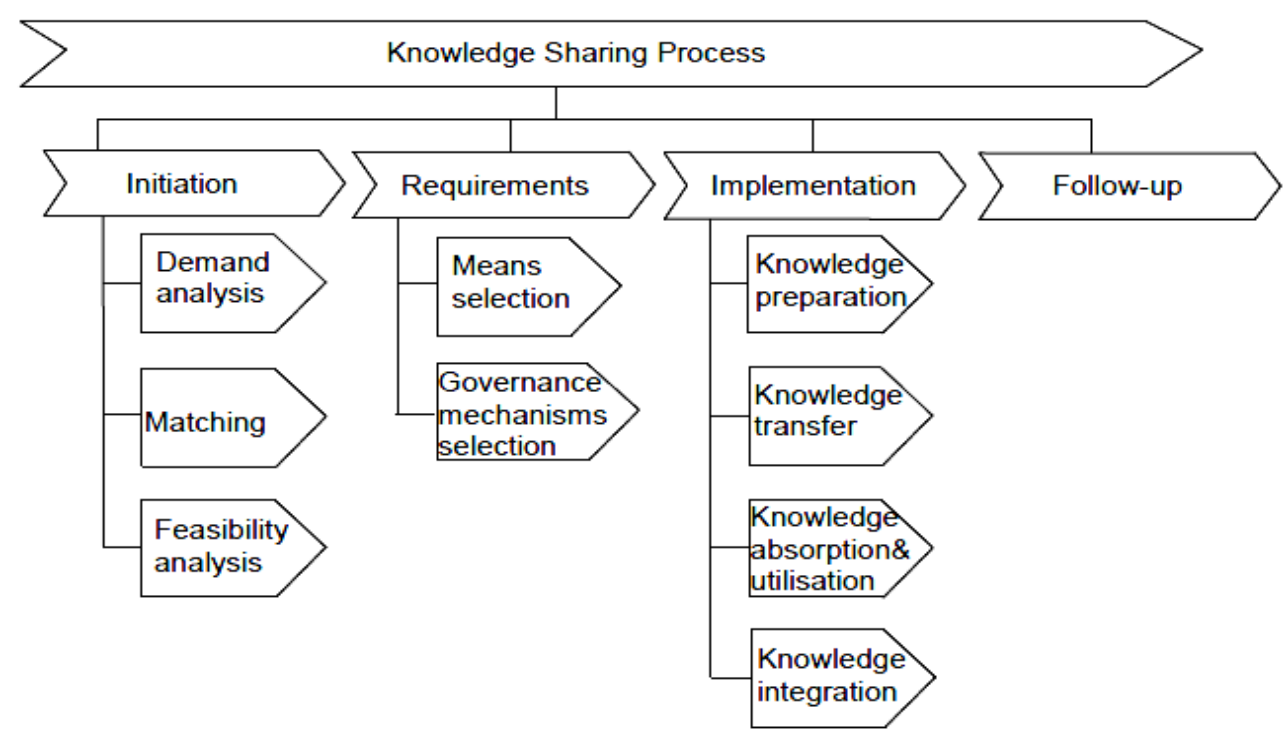

Initiation stage is the beginning of the knowledge sharing. In this stage, the idea for the knowledge need is explored by the receiver or by the source (demand analysis). In addition, they need to search for suitable partner (Matching). Then, the partner side decides whether or not to participate in the knowledge sharing process (feasibility analysis). In the requirements stage, appropriate knowledge sharing means and corresponding knowledge sharing governance mechanisms should be chosen. Knowledge sharing takes shape during the implementation stage. Knowledge source first needs to prepare the required knowledge and then transfer that knowledge. Then knowledge receiver tries to absorb the knowledge and utilise it based on his requirements. Finally, the knowledge receiver integrates the useful part of knowledge into his own knowledge. During follow up stage, knowledge source and knowledge receiver need to evaluate the issues concerning both during the knowledge sharing process.

\section{Knowledge sharing means}

Knowledge sharing means has been described by Ruggles (1997) as technologies used to enable and improve the implementation of knowledge sharing. Not all knowledge sharing means are IT based, as everyday means such as face-to-face interactions, training, etc. can be utilised to support knowledge sharing. In this study, two different types of knowledge sharing means will be discussed: techniques and Information Communication Technologies (ICTs). For the purpose of this study, techniques are 
defined as non-IT based means and ICTs are defined as tools that facilitate the sharing of knowledge by electronic means. Tacit and explicit nature of knowledge is also taken into account in this study, as there are particular means for each of these types of knowledge. Some of the knowledge sharing means that have been identified in the literature are summarised in Table 1. This list is not conclusive; it provides an overview of knowledge sharing means adopted by healthcare organisations to share knowledge.

Table 1: Knowledge sharing means

\begin{tabular}{|c|c|c|c|}
\hline Type & Means & Definition & $\begin{array}{l}\text { Tacit/ } \\
\text { Explicit }\end{array}$ \\
\hline \multirow{4}{*}{ Techniques } & Communication Channels & $\begin{array}{l}\text { Channels for communicating } \\
\text { among staff members and between } \\
\text { staff and patients including face-to- } \\
\text { face, written communication, etc. } \\
\text { (Olsson et al., 2008) }\end{array}$ & $\begin{array}{l}\text { Tacit/ } \\
\text { Explicit }\end{array}$ \\
\hline & Social means & $\begin{array}{l}\text { A useful environment (e.g. } \\
\text { meetings) for sharing knowledge } \\
\text { (Zigan et al., 2010) }\end{array}$ & $\begin{array}{l}\text { Tacit/ } \\
\text { Explicit }\end{array}$ \\
\hline & Communities of Practice & $\begin{array}{l}\text { A group of individuals who share a } \\
\text { concern about a topic and who } \\
\text { deepen their knowledge in that area } \\
\text { by interacting on an ongoing basis } \\
\text { (Wenger, 2002) }\end{array}$ & Tacit \\
\hline & Training & $\begin{array}{l}\text { Learning opportunities provided to } \\
\text { share and receive required } \\
\text { knowledge (Zigan et al., 2010) }\end{array}$ & Tacit \\
\hline \multirow{6}{*}{ ICTs } & Social Technologies & $\begin{array}{l}\text { Cover broad types of tools, all using } \\
\text { technology to build collaboration } \\
\text { and sharing knowledge, they are } \\
\text { mainly internet-based tools (Kahn } \\
\text { et al., 2010) }\end{array}$ & Explicit \\
\hline & $\begin{array}{l}\text { Clinical Decision Support } \\
\text { Systems }\end{array}$ & $\begin{array}{l}\text { An application that analyses data to } \\
\text { help clinicians make clinical } \\
\text { decisions (Ozdemir et al., 2011) }\end{array}$ & Explicit \\
\hline & Electronic Health Record & $\begin{array}{l}\text { computerised health records to } \\
\text { improve knowledge sharing among } \\
\text { clinicians (Fichman et al., 2011) }\end{array}$ & Explicit \\
\hline & Mobile Phones & $\begin{array}{l}\text { A useful tool for sharing medical } \\
\text { knowedge by using text messaging } \\
\text { service or voice mail service (Gerber } \\
\text { et al., 2010) }\end{array}$ & Tacit \\
\hline & Personal digital assistants & $\begin{array}{l}\text { Shirt pocket sized tools that enable } \\
\text { healthcare providers to gain access } \\
\text { and share knowledge (Kahn et al., } \\
\text { 2010) }\end{array}$ & Tacit \\
\hline & Telemedicine & $\begin{array}{l}\text { Delivery of healthcare services using } \\
\text { ICTs for sharing of vital knowledge } \\
\text { for diagnosis, treatment and } \\
\text { prevention of disease and etc. (Singh } \\
\text { et al. 2010) }\end{array}$ & Tacit \\
\hline
\end{tabular}

International Journal of Management and Applied Research, 2014, Vol. 1, No. 2 
Therefore, knowledge sharing can occur through different means. Techniques are affordable as no sophisticated infrastructure is required. They are also easy to implement because of their simple and straightforward nature. However, techniques might be too slow and less effective, especially, for healthcare organisations that need accurate knowledge at the right time (Olsson et al., 2008). In contrast, the use of ICTs makes knowledge sharing more efficient, faster, and more convenient (Ruikar et al., 2007). These types of knowledge sharing means have the potential to greatly facilitate knowledge access, improve communication, eliminate double documentation, and as a result increase quality of healthcare services in the long run (Gerber et al., 2010). Although ICTs play a significant role in facilitating knowledge sharing, they are not easy to implement due to the requirement of IT infrastructure and IT skills. Also, they are expensive and difficult to acquire and maintain (Aron et al., 2011).

\section{Knowledge sharing governance mechanism}

Governance mechanism refers to the governance structures and coordination mechanism to facilitate KM activities i.e. knowledge creation, knowledge sharing, etc. (Grandori, 2001). At present, many studies have investigated knowledge sharing governance mechanisms so as to favourably impact knowledge sharing. These factors can be categorised into different groups: organisational culture, technical support, and organisational context (Aron et al., 2011; Guah and Currie, 2004; Sensky, 2002; Currie and Suhomlinova, 2006). General speaking, these three aspects of governance mechanisms of knowledge sharing are used to resolve two problems: 1) how to motivate relevant actors to participate in the knowledge sharing process, 2) how to make the knowledge sharing process be efficiently conducted. In our study, the governance mechanisms for resolving the first problem are considered as motivational factors, and those for resolving the second problem are considered as supportive factors.

Motivational factors mainly provide an incentive effect for knowledge sharing and they include organisational culture. This incentive factor contributes to influencing the knowledge source and receiver intention to participate in the knowledge sharing process. On the other hand, supportive factors provide supportive conditions for knowledge sharing as to guarantee knowledge sharing proceeding forward. Organisational context and technical support are among this group. Knowledge sharing governance mechanisms are shown in Figure 3. It is highlighted that most of the knowledge sharing governance mechanisms in hospitals are not different from those identified in other industries (Sensky, 2002; Nicolini et al., 2008). 
Figure 3: Governance mechanisms of knowledge sharing Supportive factors

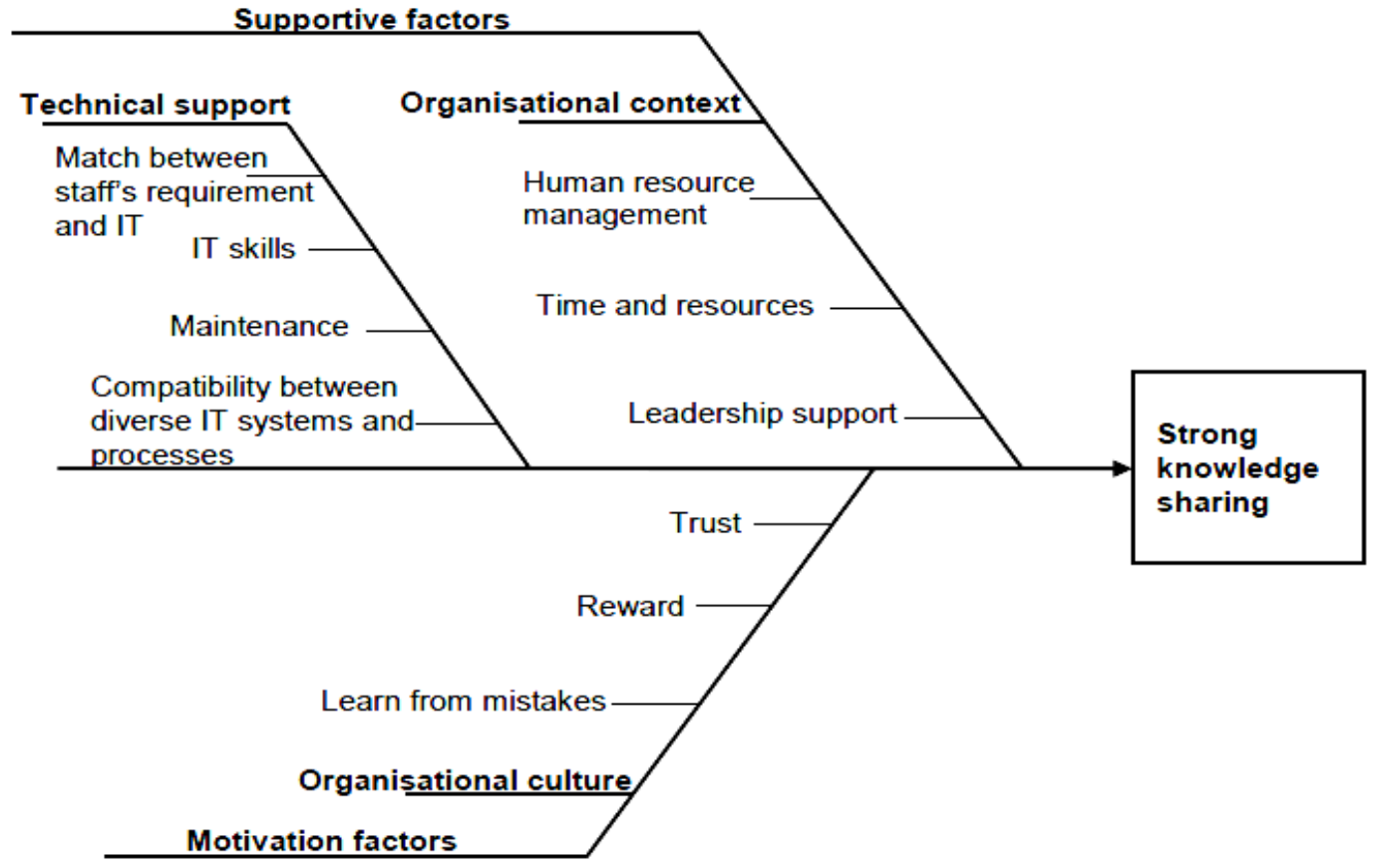

Source: Based upon literature review

Technical support: Many scholars emphasize the role of ICTs as valuable means for facilitating the knowledge sharing and communication by reducing time and distance and consequently increasing the quality and reach of reliable knowledge (Fichman et al., 2011). The key issue, however, is to choose and implement appropriate ICTs that provide a close fit between workers and their requirements. Sufficient technology skill, maintenance of ICT systems, and compatibility between ICTs and processes are also reported as a cause of strong knowledge sharing. Lack of any of these issues can lead to knowledge sharing failure even with having appropriate ICTs in place (Bradley et al., 2012; Aron et al., 2011; Guah and Currie, 2004).

Organisational context: Organisational context play a significant role in supporting knowledge sharing practices (Hislop, 2007). Leadership support, time and resources, and human resource management are reported as the main factors of organisational context in the literature. Leaders set the example for others, they have a direct impact on the organisational culture and how the organisation approaches and deals with knowledge sharing practices (Sensky, 2002). It is also important that hospitals offer enough time and resources to allow staff to share their knowledge (Currie and Suhomlinova, 2006). Furthermore, people are the core of creating organisational knowledge, because it is people who create and share knowledge. Therefore, it is critical to manage those who are willing to create and share knowledge (Sensky, 2002).

Organisational culture: The biggest challenge for hospitals actually lies in building an environment in which professional communities can trust each other; otherwise they are unlikely to share their knowledge (Dean, 2002). Tolerance of making mistakes also plays a significant role in the knowledge sharing, especially in healthcare. Since healthcare professionals are harshly blamed for errors, they hesitate to report errors. 
However, if hospitals create an environment in which mistakes can be tolerated, professionals will be motivated to report errors and learn from them to improve quality services (Currie and Suhomlinova, 2006). Reward is also very important to motivate actors to participate in knowledge sharing. Knowledge sharing participants need to see benefit for themselves in the knowledge sharing process. Otherwise, they can abandon knowledge-sharing process when they face the first problem in sharing/receiving knowledge (Lin and Chang, 2008).

\section{Knowledge sharing influencing factors relationship}

So far it is clear that knowledge sharing process could only occur when appropriate knowledge sharing governance mechanisms and knowledge sharing means are in place. First all necessary actors need to align their interest in participating in knowledge sharing process. To do this, they need to be supported and motivated by organisational and cultural issues to overcome their obstacles (Sensky, 2002). Take time for example. If knowledge source/receiver does not have enough time to share/receive knowledge, knowledge sharing cannot be implemented. Therefore, knowledge sharing governance mechanisms have direct impact on knowledge sharing process.

Second, when all actors decide to participate in knowledge sharing process, they need to adopt appropriate knowledge sharing means to share knowledge from source to receiver. Content and richness of knowledge should be handled by knowledge sharing means (Zigan et al., 2010). Thus, it is very important to choose appropriate knowledge sharing means. As a result, knowledge sharing means directly prompt knowledge sharing process forward. However, the challenge of taking advantage of knowledge sharing means, especially ICTs, is to integrate them with different aspects of knowledge sharing. Hospitals can encounter weak knowledge sharing process even by adopting appropriate knowledge sharing means due to the lack of organisational, cultural and technical support (Nicolini et al., 2008). Hospitals invest in ICTs to enable knowledge sharing, since they believe knowledge is crucial for their success (Sensky, 2002). However, if these means are not supported by technical support, knowledge sharing can be limited. Also, organisational and cultural issues influence the choice and usage of the knowledge sharing means by motivating the willingness and cognition of knowledge sharing actors, which will further impact the knowledge sharing process.

Finally key concepts from the literature are integrated into a model to identify mechanisms and elements, when present/absent, that contribute to a strong or weak approach of knowledge sharing in complex environments such as hospitals (Figure 4). This model provides organisations and policy makers with a framework to better understand how strong knowledge sharing can be achieved with the presence of appropriate knowledge sharing means and knowledge sharing governance mechanisms. Especially, the four steps of translation help to expose the success or failure causes step by step. This work intends to apply this model as a core analytical framework for investigating EKS which will be explained in the following section.

International Journal of Management and Applied Research, 2014, Vol. 1, No. 2 
Figure 4: Proposed Model for Describing Knowledge Sharing

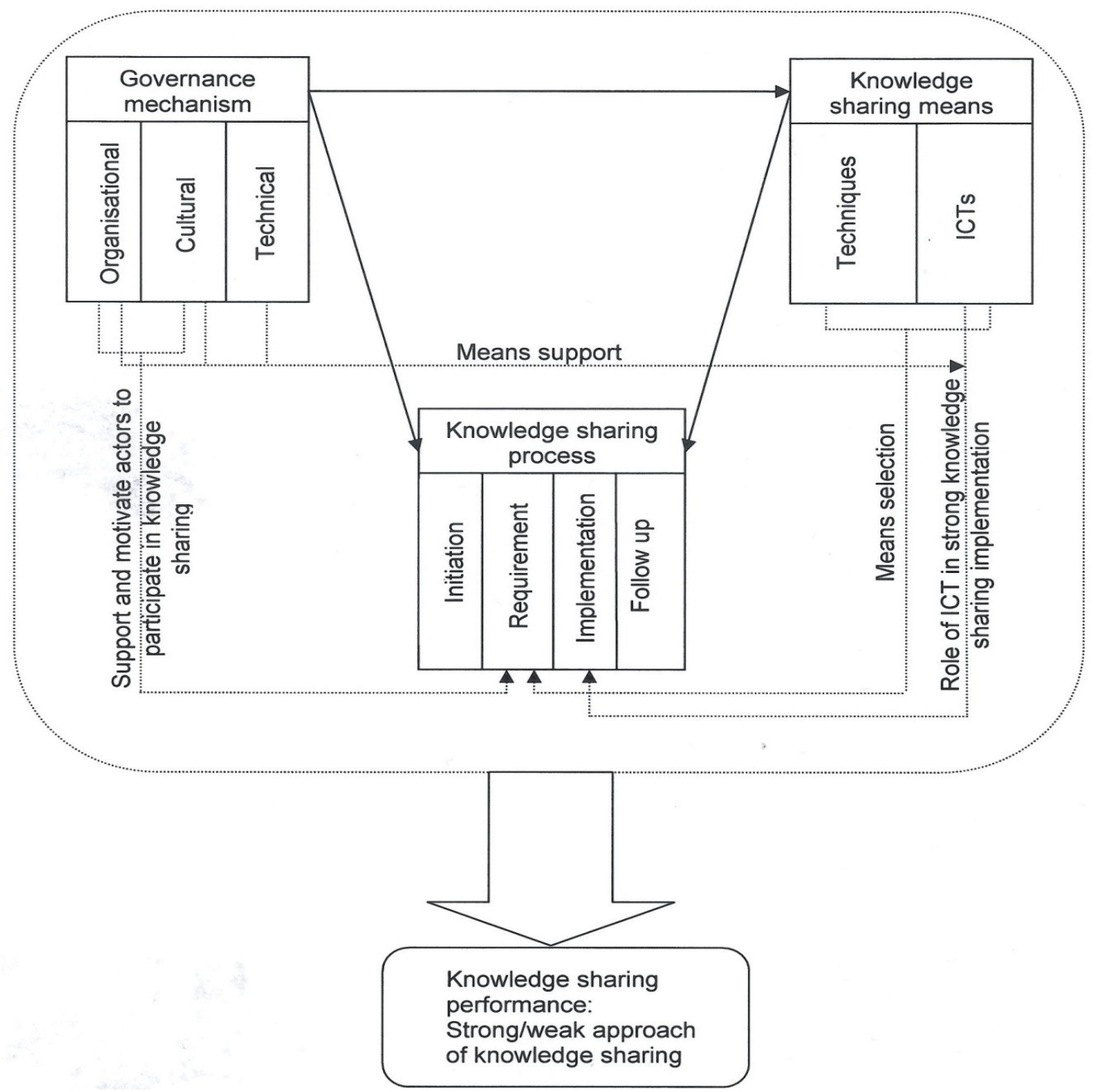

\section{Experience knowledge sharing}

This section intends to expose EKS in the selected hospital. The proposed model is provided as a critical tool to depict why strong or weak EKS is achieved. In explaining detailed causes of strong or weak EKS, the four steps of knowledge sharing process are selected as the lens of this investigation. Consequently, the causes of strong or weak EKS can be described step by step from initiation, requirement, implementation, and follow up.

\subsection{Initiation stage}

Firstly, initiation stage is the stage that describes initiation of the knowledge source or receiver to create the EKS process, and how that actor identifies the other actors involved from its point of view. At the selected hospital this stage is partially successful. The reasons of that are explained as follows: 
Demand Analysis: this stage involves all the events that lead to the attempt to initiate EKS. From interviews it was evident that, staff are mainly motivated and supported to start EKS.

At the selected hospital, senior doctors and managers create an open environment wherein junior doctors and nurses feel free to ask questions. This supports juniors effectively communicate with seniors, as there is no fear of appearing incompetent:

I'm quit happy to go and say look I don't really know what to do at this situation can you come and help me.

Personal benefits such as enjoyment from helping others and earning respect were found as a motivational factor to start EKS. In the healthcare industry people work in a team, therefore they enjoy helping their colleagues and consequently being respected.

From interviews patient safety was also shown as a significant factor to motivate clinicians to decide to start the EKS. This illustrates clinicians wish for good outcomes not only for themselves but also for patients:

What motivates me is patient care. I'm quit passionate about patient care. The only time you can see me stress out is when I don't think patient is getting the proper care. So, you want to make sure you teach the team as best as you can.

Independency is another factor that motivates actors to initiate the EKS. Fieldwork confirmed that clinicians are willing to share or learn more because it gives them the freedom to do their job more independently. From the seniors' point of view, independency of the juniors will give them more freedom to do their own job. This illustrates that juniors will also be able to do their job quicker.

Matching: this stage begins with an attempt to search for a suitable partner. From the interviews, it was evident that due to the time limitation, clinicians prefer to receive or share knowledge with ones who are more accessible:

You never have time, ease of access [is very important]. If somebody is there it's great, I'll ask. It doesn't matter if I have a good relationship with them or not. Just quicker I get the information the better.

Interviews also revealed that clinicians tend to seek partners with similar characteristics to them. At this hospital, experience knowledge flows best when the knowledge source and the knowledge receiver are from the same profession. For example, nurses prefer to communicate with nurses and doctors prefer to ask from doctors, etc.

Reliability of the partner was also seen as a determinant for successful matching. From the interviews, clinicians prefer to receive the experience knowledge from ones who are more reliable and knowledgeable.

Feasibility analysis: at this stage the above steps are revisited from the partner side to decide whether or not to participate in EKS. Findings confirmed that in most of the cases clinicians are willing to help when they are asked for help. This is because there is a mutual trust between the staff. This mutual trust establishes a positive attitude about 
participating in EKS. Because the clinicians know that their colleagues will not take advantage of their knowledge. Patient safety also motivates the clinicians. Most of the clinicians want their colleagues to know the best practices and provide the best care to patients. However, the interesting point here is that while patient safety motivates the clinician to participate in EKS, sometimes it slows down experience knowledge transfer. Clinicians deal with the human lives and wellness, therefore they need to be very careful. As a result, sometimes senior staffs do not give the juniors the chance to practice. This slows down the process of learning:

The thing with medicine is you have the responsibility for the patients.

You can't play a lot, the patient will die! So, you need small and careful steps. ... [therefore] what you can learn in weeks it can take you years.

From the interviews it was evident that workload also slows down the EKS. This causes the clinicians sometimes not being able to share or receive the experience knowledge quickly:

And it's more related to work load, it's not like they don't want to share their knowledge. I don't think they don't want to talk about, it's just working load which slow down the process.

Our fieldwork also confirmed that knowledge lost is another factor that impacts the decision of the clinicians to participate in EKS. Transfer of experience knowledge sometimes requires numerous exchanges which depend on ease of communication. From the interviews there are some cases that juniors were willing to learn new skills and experiences, but seniors could not pass the knowledge directly to them. Because that knowledge was product of many individuals and resources and therefore there was a risk of knowledge lost:

... rather than me bringing the massage then me bringing another massage back, you know, even that cannot be safe. Because, you know, you got many lines of communication, you know, it's like Chinese widespread where the message can get lost if too many people in the part as well.

From the above discussion, it is clear that although there are some issues that slow down the process of EKS, the initiation stage is completed and it enters the requirement stage. Because identified barriers are not perceived as a major stumbling block to initiate the EKS.

\subsection{Requirement stage}

The requirements needed for EKS are discussed at this stage. Like for other types of knowledge, knowledge sharing means is the main required resource for EKS. From the interviews we found that face-to-face communications and training are the main method of EKS at the selected hospital. Most of the time senior staffs teach the juniors on the ward. However, for the more serious issues staffs are sent to appropriate trainings and are taught by expertise and professionals:

We teach each other things on the ward, usually practical things. ... you can go to management and put you on training. 
Now the key issue is to make sure if other resources and requirements are available. Interviewees all confirmed that there are enough funds available at the hospital for the training sessions. Wherever staffs need to be trained for a specific task or skill, appropriate training sessions are available within the hospital. However, when it comes to face-to-face communications, the challenge is that everybody is busy. Interviewees acknowledged that there is shortage of staff in their hospital. This means that clinicians have more workload and sometimes they do not have enough time to allocate for EKS. Interviews confirmed that at these situation clinicians postpone the sharing of experience knowledge:

All the capacity is there, I think all the mechanisms are there it's just probably, you know, we need more people to do the EKS more efficiently really.

The above discussion clarifies that not all the requirements of the EKS are available. This does not mean that EKS is not implemented at the selected hospital, but it means that implementation stage occurs with delay.

\subsection{Implementation stage}

The actual EKS takes place at this stage:

Knowledge preparation: at this step, the knowledge source prepares the required experience knowledge. Interviews revealed that to do this the knowledge source first collects the necessary parts of the experience knowledge and then parcels them up in order to meet the receivers' knowledge requirement.

Knowledge transfer: as mentioned earlier the required experience knowledge is transferred via face-to-face communications or trainings. Interviewees were all happy with these methods for EKS. Because if they face any problem or do not understand something, they have the opportunity to raise and deal with that straightaway and make sure nothing is missing. Therefore, the meaningful and reliable knowledge can be transferred.

Knowledge absorption and utilisation: the knowledge receivers absorb the experienced knowledge transferred at this step. First they utilise the transferred knowledge based on their own requirements. It means that they remove the noise or disturbance in the shared knowledge to obtain the useful part of it.

Knowledge integration: at this step, knowledge receivers integrate the useful part of experience knowledge into their knowledge and apply that knowledge in their day-today job.

\subsection{Follow up stage}

This stage begins when knowledge receivers start using the experience knowledge. During this stage, the knowledge source should check whether or not the satisfactory result is achieved, or identify and resolve unexpected problems that actors might face during the use of new experience knowledge. Interviews confirmed that due to the patient safety, follow up stage is taken quite seriously at this hospital:

International Journal of Management and Applied Research, 2014, Vol. 1, No. 2 
... the next time it needs to be done again I will let them do it and I just watch them and if they face any problems I rectify them.

The study result suggests that EKS at the selected hospital can be classified as rather strong. In applying the four stages of knowledge sharing process in the experience knowledge analysis, it could be said that since the actors involved in the EKS are identified motivated and supported, meaningful and reliable experience knowledge is shared at this hospital. However, sometimes the experience knowledge cannot be transferred as quick and easy as possible due to the lack of some organisational and cultural elements.

Interplay among knowledge sharing process, knowledge sharing means, and knowledge sharing governance mechanisms, which contributes to a rather strong EKS at the selected hospital is presented in This demonstrates how the proposed model of the study (Figure 4), is applied into the healthcare industry to analyse the reasons of a rather strong EKS at the selected hospital. In Figure 5, green arrows present the enablers of EKS and amber arrows show the causes of the delay in implementation of EKS.

Figure 5: Interaction among knowledge sharing process, knowledge sharing means, and knowledge sharing process to make EKS

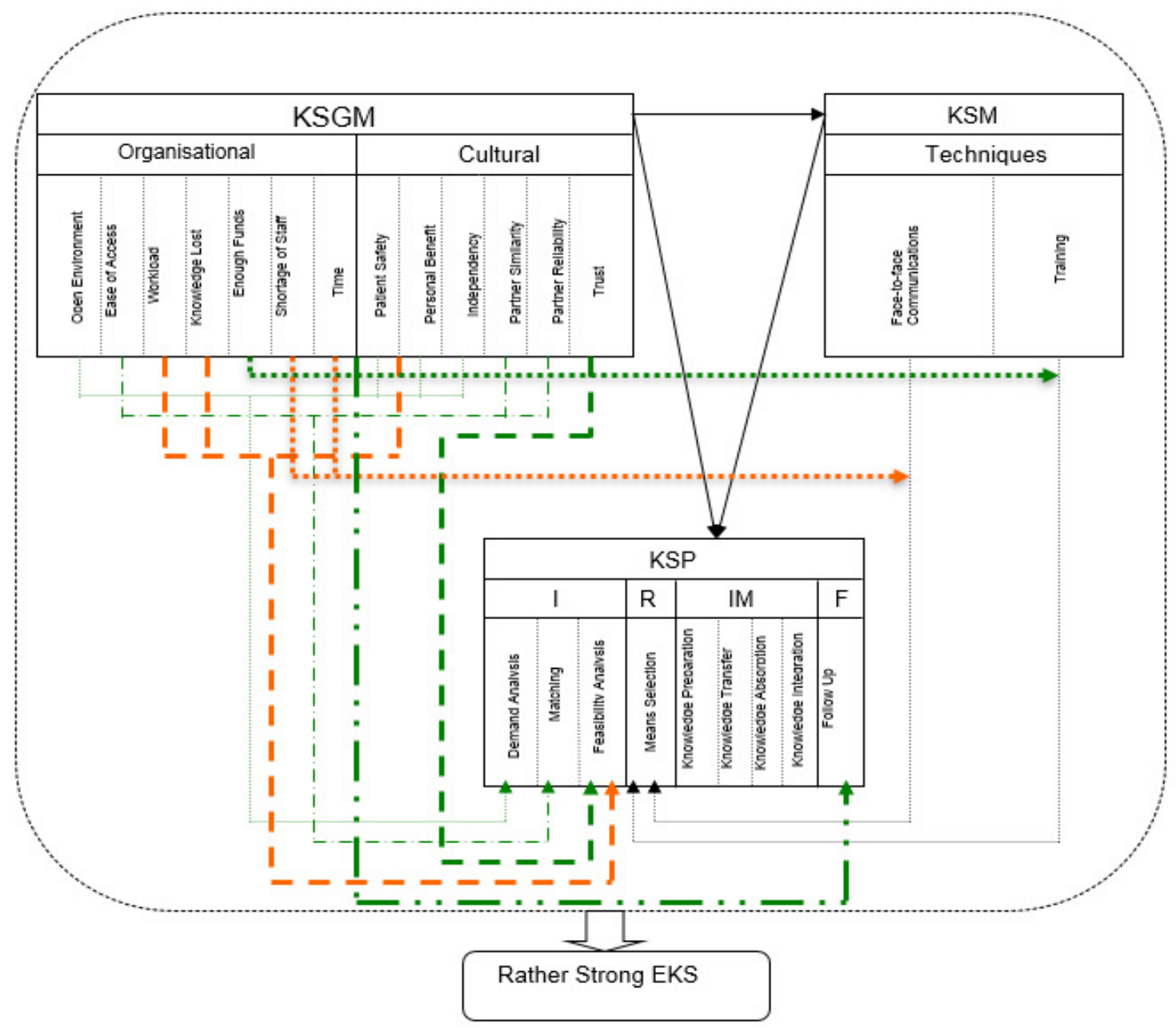

International Journal of Management and Applied Research, 2014, Vol. 1, No. 2 


\section{Conclusion}

Strong approach of knowledge sharing supports the day-to-day activities in knowledge intensive organisations such as the healthcare industry. This study integrates key concepts from the literature into a model to explain a strong approach of knowledge sharing. It is proposed that knowledge-sharing performance is influenced by the impact of knowledge sharing means and knowledge sharing governance mechanisms on the knowledge sharing process. An analysis of these three aspects of knowledge sharing has been carried out and their relationship among them explored. Knowledge sharing means impact knowledge sharing process directly. Knowledge sharing governance mechanisms not only directly impacts the knowledge sharing process but also indirectly influences the choice and usage of knowledge sharing means. These three kinds of interrelated influencing factors of knowledge sharing have an impact on knowledge sharing performance as shown in our model, 
Figure 4. The propose model of our study can help organisations and individuals from all industries better understand knowledge sharing influencing factors from different perspectives, and take valuable insight of how to choose the appropriate mans and governance mechanisms to enable knowledge sharing process more effectively.

This paper applied the propose model of the study as a critical theoretical tool for understanding EKS in the healthcare industry. In applying this model in knowledge sharing analysis, it could be said that this model expands the understanding of EKS in various dimensions. It can state that every stage of knowledge sharing process is very important to knowledge sharing and could be destabilised at any stage. A flaw or defect in one stage can disturb knowledge sharing at a later stage. EKS analysis from the earlier section shows that how the absence of some organisational and cultural factors in the initiation and requirement stage delayed the implementation of the experience knowledge.

Like other studies, this paper may naturally have limitations. First, the face-to-face interviews are very time-consuming and therefore limited to small numbers of participants. Further studies are needed to explore EKS in more hospitals as to increase the solidity of the results. Second, the viewpoints we put forward are only based on the analysis of the EKS. We need more research to analyse other types of knowledge i.e. scientific knowledge, incident knowledge, etc. Last, we illustrate the proposed model of the study in the healthcare industry. We suspect that the model would be applicable in other industries. Future studies should however explore the model in different contexts.

\section{References}

1. Alavi, M. and Leidner, D.E. (2001), "Review: Knowledge Management and Knowledge Management Systems: Conceptual Foundations and Research Issues", MIS Quarterly, Vol. 25, No. 1, pp. 107-136. https://doi.org/10.2307/3250961

2. Aron, R., Dutta, S., Janakiraman, R., and Pathak, P.A. (2011), "The Impact of Automation of Systems on Medical Errors: Evidence from Field Research", Information Systems Research, Vol. 22, No. 3, pp. 429-446. https://doi.org/10.1287/isre.1110.0350

3. Awad, E.M. and Ghaziri, H.M. (2007), Knowledge Management, Delhi: Dorling Kindersley.

4. Bradley, R.V., Pratt, R.M.E., Byrd, T.A., Outlay, C.N., and Wynn, J.,Donald E. (2012), "Enterprise Architecture, IT Effectiveness and the Mediating Role of IT Alignment in US Hospitals", Information Systems Journal, Vol. 22, No. 2, pp. 97 127. https://doi.org/10.1111/j.1365-2575.2011.00379.x

5. Busby, J.S. (1999), “An Assessment of Post-Project Reviews”, Project Management Journal, Vol. 30, No. 3, pp. 23-29. 
6. Carayannis, E. (2005), "Fostering Synergies between Information Technology and Managerial and Organisational Cognition: The Role of Knowledge Management", in Nonaka, I. (Ed), Knowledge Management: Critical Perspectives on Business and Management. Taylor \& Francis, New York, pp. 141-162.

7. Currie, G. and Suhomlinova, O. (2006), “The Impact of Institutional Forces upon Knowledge Sharing in the UK National Health Service: The Triumph of Professional Power and the Inconsistency of Policy", Public Administration, Vol. 84, No. 1, pp. 1-30. https://doi.org/10.1111/j.0033-3298.2006.00491.x

8. Davenport, T.H. and Prusak, L. (1998), Working Knowledge: How Organisations Manage What They Know, Boston: Harvard Business School Press.

9. Dean, B. (2002), "Learning from Prescribing Errors", Quality and Safety in Health care, Vol. 11, No. 3, pp. 258-260. https://doi.org/10.1136/qhc.11.3.258

10. Fichman, R.G., Kohli, R., and Krishnan, R. (2011), "The Role of Information Systems in Healthcare: Current Research and Future Trends", Information Systems Research, Vol. 22, No. 3, pp. 419-428. https://doi.org/10.1287/isre.1110.0382

11. Gerber, T., Olazabal, V., Brown, K., and Pablos-Mendez, A. (2010), “An Agenda for Action on Global E-health", Health Affairs, Vol. 29, No. 2, pp. 233-236.

12. Grandori, A. (2001), "Neither Hierarchy Nor Identity: Knowledge Governance Mechanisms and the Theory of the Firm", Journal of Management and Governance, Vol. 5, No. 3/4, pp. 381-399. https://doi.org/10.1023/A:1014055213456

13. Guah, M.W. and Currie, W.L. (2004), "Factors Affecting IT-Based Knowledge Management Strategy in the UK Health Care System", Journal of Information and Knowledge Management, Vol. 3, No. 4, pp. 279-290. https://doi.org/10.1142/S0219649204000900

14. Hansen, M.T. (1999), "The Search-Transfer Problem: The Role of Weak Ties in Sharing Knowledge across Organisation Sub-Units", Administrative Science Quarterly, Vol. 44, No. 1, pp. 82-111. https://doi.org/10.2307/2667032

15. Hendriks, P. (1999), "Why Share Knowledge? The Influence of ICT on the Motivation for Knowledge Sharing", Knowledge and Process Management, Vol. 6, No. 2, pp. 91-100. https://doi.org/10.1002/(SICI)1099-1441(199906)6:2<91::AIDKPM54>3.0.CO;2-M

16. Hislop, D. (2007), "Knowledge Processes and Communication Dynamics", in McInerney, C.R. and Day, R.E. (Ed), Rethinking Knowledge Management: From knowledge objectives to knowledge processes, Heidelberg: Springer, pp. 187-208.

17. Ho, K., Bloch., R., Gondocz, T., Laprise, R., Perrier, L., Ryan, D., Thivierge, R., and Wenghofer, E. (2004), "Technology-Enabled Knowledge Translation: Framework to Promote Research and Practice", Journal of Continuing Education in 
the Health Professions, Vol. 24, No. 2, pp. 90-99.

https://doi.org/10.1002/chp.1340240206

18. Kamara, J., Anumba, C., and Carillo, P. (2002), "Learning to Learn, from Past to Future”, International Journal of Project Management, Vol. 20, No. 3, pp. 205-211. https://doi.org/10.1016/S0263-7863(01)00071-0

19. Kankanhalli, A., Tan, B.C.Y. and Wei, K. (2005), "Contributing Knowledge to Electronic Knowledge Repositories: An Empirical Investigation", MIS Quarterly, Vol. 29, No. 1, pp. 113-143.

20. Kilo, C.M. (2005), "Transforming care: Medical Practice Design and Information Technology", Health Affairs, Vol. 24, No. 5, pp. 1296-301.

21. Leonard-Barton, D. (1995), Wellsprings of Knowledge, Boston: Harvard Business Press.

22. Lin, C., and Chang, S. (2008), "A Relational Model of Medical Knowledge Sharing and Medical Decision-Making Quality", International Journal of Technology

Management, Vol. 43, No. 4, pp. 320-348.

https://doi.org/10.1504/IJTM.2008.020554

23. Lin, B. and Hsieh, C.T. (2006), "Critical Factors for Assessing Service Quality of Online Pharmacies: A Research Framework", International Journal Electronic Healthcare, Vol. 2, No. 4, pp. 398-414. https://doi.org/10.1504/IJEH.2006.010428

24. Lin, L.H., Geng, X.J. and Whinston, A.B. (2005), "Sender-Receiver Framework for Knowledge Transfer”, MIS Quarterly, Vol. 29, No. 2, pp. 197-219.

25. Mansingh, G., Osei-Bryson, K., and Reichgelt, H. (2009), "Issues in Knowledge Access, Retrieval and Sharing - Case Studies in a Caribbean Health Sector", Expert Systems with Applications, Vol. 36, No. 2, pp. 2853-2863.

https://doi.org/10.1016/j.eswa.2008.01.031

26. Miller, R.H. (2012), "Satisfying Patient-Consumer Principles for Health Information Exchange: Evidence from California Case Studies", Health Affairs, Vol. 31, No. 3, pp. 537-47.

27. Nicolini, D., Powell, J., Conville, P. and Martinez-Solano, L. (2008), "Managing Knowledge in the Healthcare Sector. A Review", Journal of Management Reviews, Vol. 10, No. 3, pp. 254-263. https://doi.org/10.1111/j.1468-2370.2007.00219.x

28. Nonaka, I., Toyama, R. and Nagata, A. (2000), "A Firm as a Knowledge-Creating Entity: A New Perspective on the Theory of the firm", Industrial and Corporate Change, Vol. 9, No. 1, pp. 1-20. https://doi.org/10.1093/icc/9.1.1

29. Norman, D. A. (1998), The Design of Everyday Things, $3^{\text {rd }}$ ed., New York: MIT Press. 
30. Olsson, E., Wismen, M. and Carlsson, S. (2008), "Permanent and temporary work practices: knowledge integration and the meaning of boundary activities", Knowledge Management Research \& Practice, Vol. 6, No. 4, pp. 260-273. https://doi.org/10.1057/kmrp.2008.27

31. Poston, R.S. and Speier, C. (2005), "Effective Use of Knowledge Management Systems: A Process Model of Content Ratings and Credibility Indicators", MIS Quarterly, Vol. 29, No. 2, pp. 221-244.

32. Ruggles, R.L. (1997), Knowledge Management Tools, Boston: ButterworthHeinemann.

33. Ruikar, K., Anumba, C.J., and Egbu, C. (2007), "Integrated Use of Technologies and Techniques for Construction Knowledge Management", Knowledge Management Research \& Practice, Vol. 5, No. 4, pp. 297-311. https://doi.org/10.1057/palgrave.kmrp.8500154

34. Sensky T. (2002), "Knowledge Management", Advances in Psychiatric Treatment, Vol. 8, No. 5, pp. 387-395. https://doi.org/10.1192/apt.8.5.387

35. Sim, I., Gorman, P., Greenes, A., Haynes, R.B., Kaplan, B., Lehmann, H., and Tang, P.C. (2001), "Clinical Decision Support Systems For The Practice Of EvidenceBased Medicine", Journal of the American Medical Informatics Association, Vol. 8, No. 6, pp. 527-534.

36. Stead, W. and Lin, H. (2009), Computational Technology for Effective Healthcare: Immediate Steps and Strategic Directions, Washington, DC: The National Academic Press.

37. Szulanski, G. (1996), "Exploring Internal Stickiness: Impediments to the Transfer of Best Practice within the Firm", Strategic Management Journal, Vol. 17, No. S2, pp. 27-43. https://doi.org/10.1002/smj.4250171105

38. Zigan, K., Macfarlane, F., and Desombre, T. (2010), "Knowledge Management in Secondary Care: A Case Study", Knowledge and Process Management, Vol. 17, No. 3, pp. 118-127. https://doi.org/10.1002/kpm.347 